Int. J. Dev. Biol. 53: 259-268 (2009)

doi: $10.1387 / \mathrm{ijdb} .082673 \mathrm{ae}$

\title{
The secret message of heterochromatin: new insights into the mechanisms and function of centromeric and pericentric repeat sequence transcription
}

\author{
ANGELINE EYMERY, MARY CALLANAN* and CLAIRE VOURC' $\mathrm{H}^{*}$ \\ Université Joseph Fourier, INSERM, Institut Albert Bonniot, U823, F-38706, Grenoble, France
}

\begin{abstract}
In the fission yeast, $S$. Pombe, small dsRNA generated by RNAi-dependent mechanisms are involved in the establishment and maintenance of heterochromatic regions. The existence of conserved features within the general organization of centromeric and pericentromeric repeats in yeast, mouse and human argues in favor of a conserved role for centromeric and pericentromeric-derived transcripts across these species. In support of this, evidence is accumulating that centromeric and pericentromeric sequences are transcriptionally competent in diverse biological contexts in mammalian cells. Given the importance of centromeric and pericentromeric regions, not only with respect to centromere function, but also to gene regulation, this review examines the biological contexts in which mouse and human centromeric and pericentromericspecific transcripts have been observed. The structure of the transcripts generated, the molecular mechanisms underlying their expression and their supposed functions will be discussed.
\end{abstract}

KEY WORDS: heterochromatin, satellite sequence, transcription, epigenetics, RNA processing

\section{Introduction}

It has recently been discovered that RNA is an essential component of constitutive heterochromatin (Maison et al., 2002; Muchardt et al., 2002). This has spurred several groups to search for specific transcripts likely to participate in heterochromatin structure. Fission yeast is the only organism in which a specific RNA fullfiling this function has been identified. Indeed, in S.pombe, small dsRNA generated by RNAi-dependent mechanisms are involved in the establishment and maintenance of heterochromatic regions (Fig. 1). Strikingly, these RNAs are encoded by PCT regions which have long been thought to be transcriptionally silent (Grewal and Elgin, 2007).

This exciting discovery adds a new dimension to our current view of how CT and PCT sequences participate to the formation, maintenance and function of specific constitutive heterochromatin structures such as centromeres. By highly conserved mechanisms, CT repeats are known to load the histone variant cenH3, together with specific centromeric proteins required for kinetochore formation, to centromeres. Likewise, PCT regions are enriched in epigenetic repressive marks, such as histone $\mathrm{H} 3$ lysine 9 trimethylation ( $\mathrm{H} 3 \mathrm{~K} 9 \mathrm{me} 3)$ and heterochromatin factors such as HP1 (Heterochromatin Protein 1), that are involved in ensuring sister chromatid cohesion until anaphase onset (Amor et al., 2004).

The existence of conserved features within the general organization of CT and PCT repeats in yeast, mouse and humans (Fig. 1) argues in favor of a conserved role for CT and PCT-derived transcripts across these species. In support of this, evidence is accumulating that $\mathrm{CT}$ and $\mathrm{PCT}$ sequences are transcriptionally competent in diverse biological contexts in mammalian cells. CT and PCT-derived transcripts have been detected throughout different stages of mammalian development and during cellular differentiation, proliferation, transformation, senescence and adaptation to environmental stress. What is less clear is whether these situations necessarily correspond to the need to form or maintain heterochromatin. Indeed, CT and PCT regions have been shown to represent centers for transcriptional repression of genes located in their vicinity, not only in cis but also in trans (Fisher and Merkenschlager, 2002) and it is possible that a transient transcriptional derepression of these regions is used by the cell as a way to modify the functional organization of the cell

Abbreviations used in this paper: CT, centromere; PCT, pericentomere.

\footnotetext{
*Address correspondence to: Dr. Claire Vourch or Dr. Mary Callanan. University Joseph Fourier, INSERM Grenoble, F-38041, France. e-mails: claire.vourch@ujf-grenoble.fr or mary.callanan@ujf-grenoble.fr
}

Published online: 20 April 2009

ISSN: Online 1696-3547, Print 0214-6282 
nucleus.

Given the importance of CT and PCT regions, not only with respect to centromere function but also to gene regulation, this review examines the biological contexts in which mouse and human CT and PCT-specific transcripts have been observed. The structure of the transcripts generated, the molecular mechanisms underlying their expression and their supposed functions will be discussed.

\section{Where and when are CT and PCT sequences expressed?}

Despite identification of satellite DNA transcription in mouse as early as the late 60s (Harel et al., 1968; Cohen et al., 1973), the structure of CT and PCT transcripts remains poorly characterized. Indeed, the repetitive nature of CT and PCT regions adds to the difficulty of their analysis. Nonetheless, in the following sections of this review, the size and transcriptional orientation of $C T$ and PCT transcripts will be indicated wherever this has been determined.

\section{Cellular response to stress}

One of the most dramatic examples of transcriptional activation of centromeric specific sequences is that which occurs in response to cell stress.

In numerous normal primary and cancer human cell lines, heat-shock has been shown to induce satellite III sequence (sat III) transcription primarily from the $9 q 12$ locus although transcription from other PCT regions has been observed particularly in tumours cells, independent of the cell cycle (Jolly et al., 1997; Denegri et al., 2002).

Controversy exists concerning the size of these polyadenylated transcripts. Indeed, sat III transcripts are either detected as very long transcripts (Jolly et al., 2004) or as a continuum of transcripts, ranging in size from more than $5 \mathrm{~kb}$ to less than $2 \mathrm{~kb}$ (Rizzi et al., 2004) thereby raising the possibility that the latter could be generated from long precursors through post-transcriptional mechanisms involving splicing (see below).

In heat-shocked cells, sat III sequences are mainly transcribed in the sense orientation although low level of antisense transcription has been detected (Fig. 2). Interestingly, low levels of sense and antisense sat III transcripts have also been detected in non heat-shocked cells. Furthermore, in both heat-shocked and non-heatshocked cells, sense transcripts are more abundant than antisense transcripts, thus suggesting that the transcriptional orientation is tightly controlled (Valgardsdottir et al., 2008).

Although originally described upon heat shock, induction of sat III expression, in a sense orientation, has recently been shown to be triggered by a wide range of stress conditions including cellular exposure to DNA damaging agents and oxidative stress (Fig. 3). Interestingly, transcript levels vary according to the nature of the stress signal. MMS, etoposide, aphidilcolin and oxidative stress are low inducers of sat III transcription, while UVC and
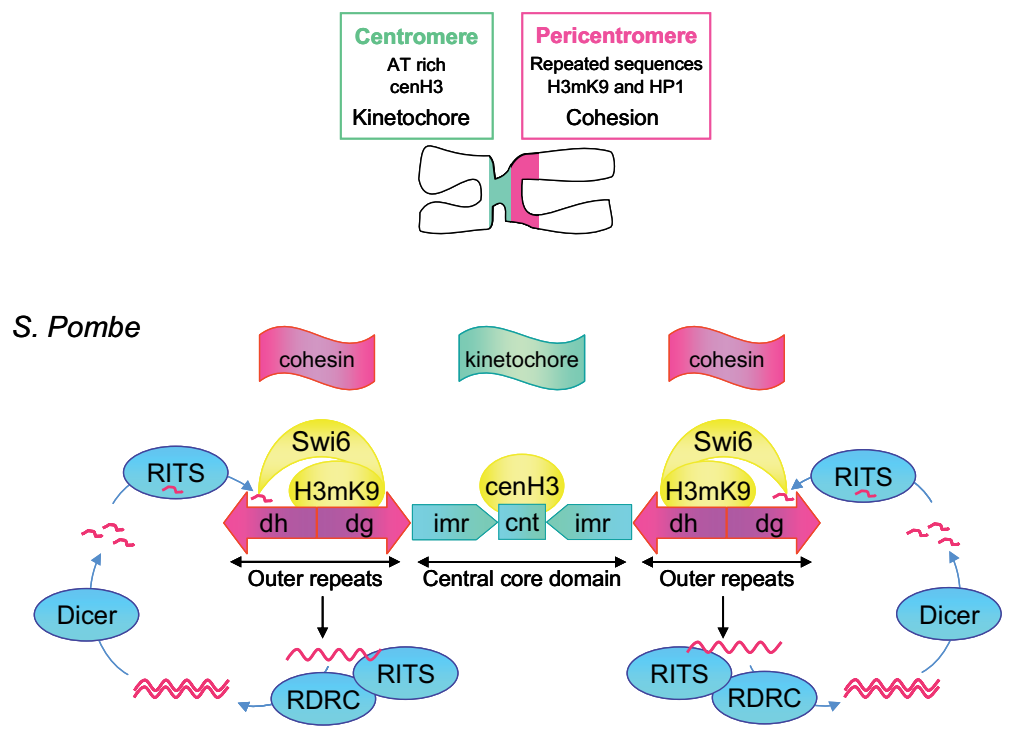

M. Musculus

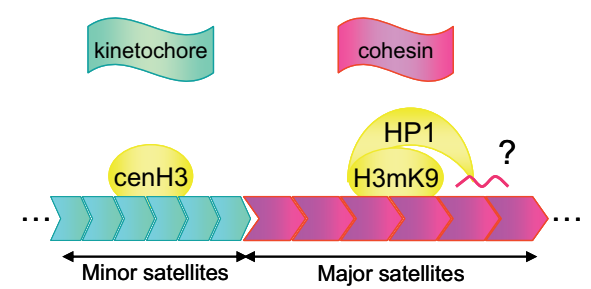

H. Sapiens

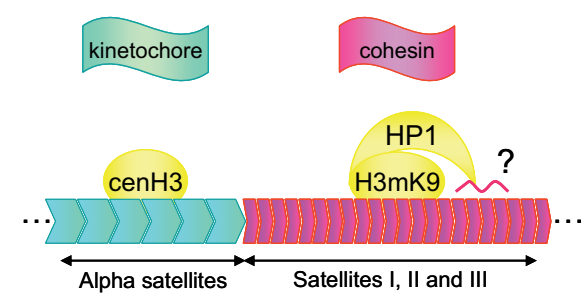

Fig. 1. Comparative organization of centromeric (CT) and pericentromeric (PCT) regions in fission yeast (S. Pombe), mouse and human chromosomes. CT (represented in green) and PCT (represented in pink) regions display a similar organization in all eukaryotes. CT regions are enriched in cenH3 (centromeric histone $\mathrm{H3}$ ) and play a direct role in spindle attachment. $P C T$ regions, which recruit the cohesin complex are enriched in $\mathrm{H} 3 \mathrm{~K} 9 \mathrm{me} 3$, swi6 (S.Pombe) and heterochromatin protein 1 (HP1) (mouse and human swi6 homolog). RNA molecules are also thought to participate to the structure of CT and PCT regions. In yeast, these RNA molecules have been characterized as small dsRNA, encoded by PCT regions, and generated by the RNAi machinery (Dicer, RITS, RDRC). In mouse and human cells, the existence and role of such transcripts is still questioned. In S.Pombe, CT regions are formed by a central core domain which contains a unique AT rich sequence of $\sim 4 \mathrm{~Kb}$ (central core) flanked by imperfect repeats (imr) of $\sim 5$ to $6 \mathrm{~Kb}$ each. PCT regions are made of outer $d h$ and $d g$ repeats of $\sim 5 \mathrm{~kb}$ each (Wood et al., 2002). In mouse, CT and PCT regions have not yet been fully characterized. CT regions of $\sim 600 \mathrm{~kb}$ are made of a repetition of AT-rich minor satellite motifs of 120pb. PCT regions of $\sim 6 \mathrm{Mb}$ are made of a repetition of AT-rich major satellite motifs of 234bp. In humans, CT regions of about $\sim 240 \mathrm{~kb}-5 \mathrm{Mb}$, depending on the chromosome considered, are made of a repetition of AT-rich alpha satellite motifs of $171 \mathrm{bp}$. The size and structure of PCT regions, which also varies between chromosomes, are made of satellite repeats of three types: type I $10.5 \%$ of the genome), type II (2\% of the genome) and type III (1.5\% of the genome). 
Mouse

\begin{tabular}{l|l|}
\hline \multicolumn{1}{c|}{ GGAAAATGATAAAAACCACACT } \\
GTAGAACATATTAGATGAGTGA \\
GTTACACTGAAAACACATTCG \\
TTGGAAACGGGATTTGTAGAAC \\
AGTGTATATCAATGAGTTACAAT \\
GAGAAACAT \\
\hline \multirow{1}{*}{ GGACCTGGAATATGGCGAGAA } \\
PACTGAAAATCACGGAAAATGA \\
GAAATACACACTTTAGGACGTG \\
AAATATGGCGAGGAAACTGAA \\
AAAGGTGGAAAATTAGAAATG \\
TCCACTGTAGGACGTGGAATAT \\
GGCAAGAAAACTGAAAATCATG \\
GAAAATGAGAACATCCACTTGA \\
GGACTTGAAAAATGACGAAATC \\
ACTAAAAACGTGAAAAATGAG \\
AAATGCACACTGAA \\
\hline
\end{tabular}

\begin{tabular}{|c|c|c|c|}
\hline \multirow{3}{*}{ РCT } & РCT & Mouse & Human \\
\hline & $\stackrel{\text { SENSE }}{\longrightarrow}$ & T-rich & GGAAT-rich \\
\hline & ANTISENSE & A-rich & ATTCC-rich \\
\hline
\end{tabular}

Human

CATTCTCAGAAACTTCTTTGTGATGTATACATT CAACTCACAGAGTTGAACCTTCCTTTTCATAG AGCAGTTTTGAAACACTCTTTTTGTAGAATCTG CAAGTGGATATTTGGACCGCTTTGAGGCCTTG GTTGGAAACGGGAATATCTTCATATAAAAACT AGACAGAAG

\section{Human}

Satellites II : (ATTCCATTCG $)_{2}+($ ATG $) 1$ or 2 Satellites III : (ATTCC) + or - (AT/GTCGGGTTG)

Fig. 2. Nucleotide sequences of mouse and human $\mathrm{CT}$ and PCT repeats. The nucleotide sequence of mouse CT (minor satellites) and PCT (major satellites) repeats is shown (Wong and Rattner, 1988) together with the nucleotide sequences of human CT (alpha satellite) and PCT (satellite of types II and III) repeats (Prosser et al., 1986; Vissel and Choo, 1987). For human and mouse, CT and PCT sequence referred to as "sense" and "antisense" in the text are also indicated. hyperosmotic stress are moderate inducers and heat shock and cadmium are strong inducers. Interestingly, increased levels of antisense sat III transcripts are only observed with the strong stress inducers (Valgardsdottir et al., 2008).

Studies assessing stress-induced sat III expression, in vivo, are currently scarce. However, one study has reported up regulation of 6 to $12 \mathrm{~Kb}$ PCT-specific transcripts - possibly linked to mitochondria-induced oxidative stress - in the heart of aging mice but not in brain, kidney or liver (Gaubatz and Cutler, 1990).

The functional role and precise molecular origin of sat III transcripts remains unclear. By analogy to what is known from studies in S. Pombe, sat III transcripts may be processed into small dsRNA that subsequently play a role in heterochromatin structure. In this scenario, the long sat III transcripts observed in heat-shocked cells might accumulate as a consequence of inhibition or saturation of the RNAi machinery concomitant with changes in their putative functional role in heterochromatin structure. In an alternative scenario, and by analogy to Xist transcripts in female X chromosome inactivation (Heard, 2004), long sat III transcripts may be involved in maintenance of specific chromatin states during cellular stress. Indeed, in heat-shocked cells, sat III transcripts, once synthesized, remain in the nucleus in close association with the $9 q 12$ locus, suggesting that they play a role, either in the protection of the $9 q 12$ locus or in the regeneration of chromatin structure following a stress.

Another hypothesis is that sat III transcripts play a role in the control of transcription and splicing during stress, through transient sequestration of key components involved in these functions (Biamonti, 2004; Jolly and Lakhotia, 2006). Indeed, several transcription (Jolly et al., 2004) and splicing factors (Chiodi et al., 2000; Denegri et al., 2001; Metz et al., 2004) co-localize and/or interact with sat III transcripts at the $9 q 12$ locus during heat shock.

Finally, since heterochromatin is thought to play a repressive influence on genes located in cis or in trans through position effect mechanisms, transcriptional activation of these huge blocks of methylated DNA may counteract their repressive influence (Fisher and Merkenschlager, 2002). By whatever mechanism this occurs, transcriptional activation of PCT regions, could represent a way to transiently modify the structural and functional organization of the cell nucleus. More detailed investigations of the origin, nature and functional role of sat III PCT transcripts in heatshocked cells offers an opportunity to resolve this important question.

\section{Development and cell differentiation}

Some insights into the potential role of PCT transcripts in mammalian development and cellular differentiation can be gleaned from expression analyses in mouse embryos and adult tissues (Rudert et al., 1995). This latter study provides intriguing evidence suggesting that PCT sense and antisense transcription is spatially and temporally regulated throughout mouse embryonic development. For example, in 11.5-15.5 dpc (day post coitum) embryos, PCT transcripts in a sense orientation (Fig. 2) are ubiquitously distributed in various tissues (Fig. 4). In particular, high level expression of PCT sequences is observed in the central nervous system (CNS) $12.5 \mathrm{dpc}$ and in scattered cells from the CNS at $15.5 \mathrm{dpc}$. Interestingly, transcripts in the opposite orientation (Fig. 2) are only observed in $11.5 \mathrm{dpc}$ embryo, in a subset of cells most likely corresponding to the same CNS cell population in which sense transcripts are also detected (Fig. 4). This suggests that accumulation of antisense PCT transcripts may somehow precede the accumulation of the same transcripts in a sense orientation in CNS cells. In adult tissues, a sense expression of PCT sequences is detected in liver and testis but not in other tissues such as brain,
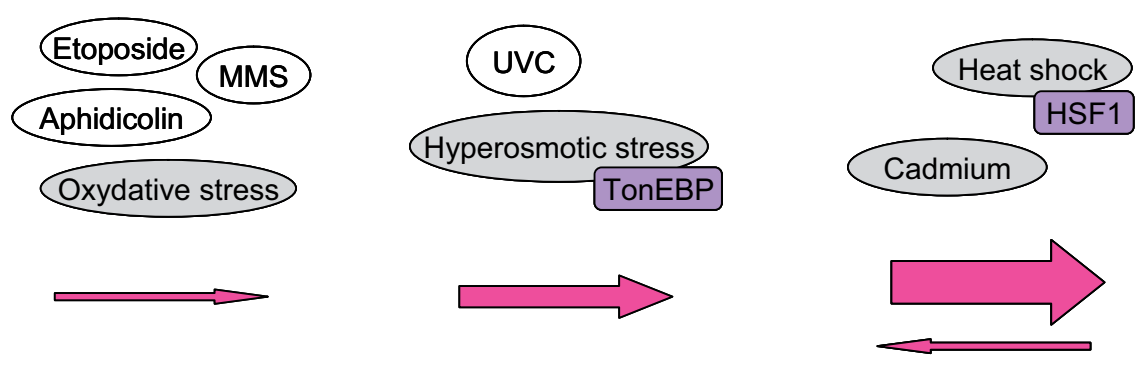

Fig. 3. Stress induced pericentromeric transcription in human cell. Genotoxic agents (white ellipses) and other stresses (grey ellipses) have been shown to induce either a low (small pink arrow), medium (intermediate pink arrow) or high (large pink arrow) transcriptional activation of PCT regions. In only two cases, heat-shock and hyperosmotic stress, transcription factors responsible for PCT activation have been formally identified (purple boxes). HSF1 is also most likely to be involved in the activation of sat III sequences in response to cadmium and oxidative stress. The orientation of the transcripts detected in each case is indicated (sense: right pointing arrow; antisense: left pointing arrow). 
colon, spleen, heart and lung, thus revealing a specific pattern of expression, not only with regard to embryonic stage, but also with regard to cell type (Fig. 4). Interestingly, transcripts in an antisense orientation are also detected in testis but only in seminiferous tubules that are devoid of mature spermatozoids. Differential expression of these transcripts in brain and testis probably coincides with specific and dramatic chromatin remodeling events occurring during cell differentiation.

More recently, expression of PCT transcripts has been described in human testis, thereby further supporting the notion that they might play an essential role in the differentiation of germinal cells. Sat III sequences from chromosome $Y$ are specifically expressed as polyadenylated RNA, ranging in size from $1 \mathrm{~Kb}$ to $20 \mathrm{~Kb}$ (Jehan et al., 2007). Interestingly, these transcripts have been shown to be implicated in transplicing events. For example, the presence of PCT sequence from chromosome $Y$ has been identified in a testicular isoform of CDC2L2 polyadenylated mRNA. Insertion/ transplicing of sat III sequence into the CDC2L2 5'UTR is thought to enhance splicing and mRNA translation of CDC2L2 mRNA, and a protection of this transcript against degradation (Jehan et al., 2007).

Finally, parallel can be drawn between transient expression of PCT transcripts in testis and expression of Piwi-interacting RNAs (piRNAs) which accumulate as 26-31nt long RNAs in germline cells at the onset of meiosis (Aravin et al., 2006; Girard et al., 2006). piRNAs which have been discovered in the mammalian and Drosophila germ lines have emerged as potent regulators of gene expression at both transcriptional and posttranscriptional levels (Lin, 2007). However, no homology between PCT transcripts and these small RNAs has been found so far (personal

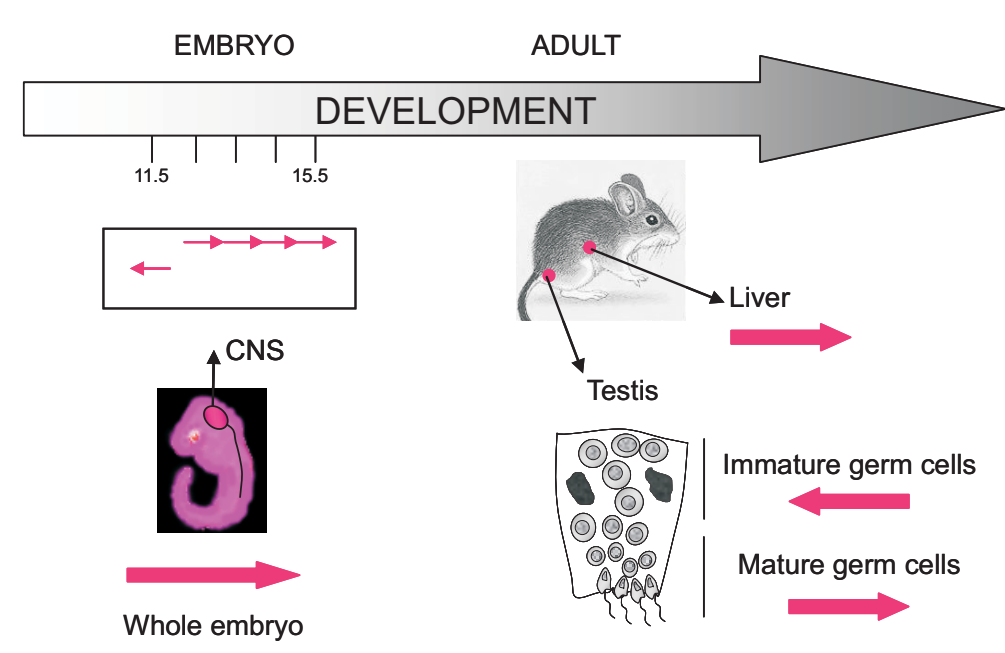

Fig. 4. Transcription of pericentromeres during mouse development. In 11.5 and $15.5 \mathrm{dpc}$ (days post coitum), PCT transcripts are detected in whole mouse embryonic tissues. In particular, high level expression of these transcripts is observed in the central nervous system (CNS) $12.5 \mathrm{dpc}$ and in scattered cells from the CNS $15.5 \mathrm{dpc}$. Interestingly, transcripts in the opposite orientation are only observed $11.5 \mathrm{dpc}$, in a subset of cells most likely to correspond to the same CNS cell population where sense transcripts are also detected. In adults, PCT transcripts are only detected in liver and testis. In testis, PCT transcripts in an antisense orientation are observed in immature germ cells while transcripts in a sense orientation are observed in mature germ cells. The orientation of the transcripts reveals a specific pattern of expression, with regard to embryonic stages and cell type. observation).

Mouse CT and PCT transcripts have also been observed upon terminal muscle cell differentiation (Terranova et al., 2005; Bouzinba-Segard et al., 2006). Specifically, CT transcripts ranging in size from less than $1 \mathrm{~kb}$ to several $\mathrm{kb}$ are present in nondifferentiated growing cells but accumulate in differentiated cells, as $\sim 120$ nt molecules. These 120nt transcripts most likely correspond to the 120bp unit found in mouse minor satellite sequences (Figures 1 and 2).

It is at present difficult to assign a precise function to CT and PCT-specific transcripts during cell differentiation. Nonetheless it is worth noting that in muscle cells, differentiation results in progressive centromere clustering and in increased levels of two heterochromatic epigenetic marks, H3K9 and H4K20 methylation at $\mathrm{PCT}$ regions. It can thus be hypothesised that accumulation of CT and PCT transcripts participates to the formation of heterochromatin during this process. The presence of CT transcripts in both orientations also suggests that they may be involved in heterochromatin structure as small 21-25nt-long dsRNA through an activation of the RNAi machinery and their targeting to longer PCT transcript precursors (Bouzinba-Segard et al., 2006).

In various cellular differentiation models, retinoic acid (RA) treatment-induced differentiation has been shown to increase or decrease PCT transcript levels. PCT transcript upregulation is observed in undifferentiated muscle or ES cells undergoing RAinduced differentiation while lower transcript levels are observed in RA-treated pluripotent embryonic carcinoma P19 cells (Rudert et al., 1995; Martens et al., 2005). These conflicting results are likely to reflect differences in the epigenetic status of P19 and ES cells and / or a differential expression of additional factors required for transcription of PCT repeats.

Further arguments are in favor of a role CT and PCT transcripts in cell differentiation. Specifically, CT transcripts accumulate within DAPI-rich PCT regions in murine erythroleukemic cells induced to differentiate (BouzinbaSegard et al., 2006). Moreover, a forced accumulation of $\sim 120$ nt CT transcripts, in a sense orientation, affects chromosome segregation and sister-chromatid cohesion, induces modifications of centromeric epigenetic hallmarks and mislocalisation of proteins essential for centromeric function. This last observation suggests that $C T$ transcripts may have the ability to interact with essential factors involved in centromere structure and function and that overexpressed CT transcripts may cause a titration of these factors, thereby leading to centromere alterations (Bouzinba-Segard et al., 2006).

\section{Cell cycle}

Analysis of the expression of PCT sequences during the cell cycle brings new interesting evidence in favor of a role of PCT transcripts in heterochromatin structure. In proliferative mouse cells, PCT specific transcripts accumulate during the course of $G 1$, reaching a peak in late $G 1$ /early $S$ phase. A decrease in the quantity of these transcripts coincident with replication of PCT heterochromatin is then observed (Lu and Gilbert, 2007). Moreover, PCT-specific transcripts, present as a heterogeneous population of molecules ranging from $1 \mathrm{~kb}$ to more than $8 \mathrm{~kb}$, accumulate on the outer surface of the chromocenters where replica- 
tion of PCT sequences occurs (Quivy et al., 2004). This observation strongly suggests that, similar to what is described in S.Pombe (Chen et al., 2008), PCT transcripts play a role in the reformation of pericentric chromatin (Lu and Gilbert, 2007).

More surprisingly, accumulation of PCT specific transcripts of smaller size ( 200nt) is also detected at the beginning of mitosis, coincident with a disruption of the interaction of transcription factors with chromatin (Prasanth et al., 2003). It is likely that transcription of PCT sequences also serves to reinforce heterochromatin structure during the late stages of mitosis when most cohesin has been removed or that they assist in the reloading of HP1, which occurs during anaphase (Wu et al., 2006). Again, it is still not known if the various populations of PCT transcripts which are detected, represent substrates for the RNAi machinery but the presence of transcripts in both orientations would tend to support an implication of this mechanism.

\section{Replicative senescence}

Expression of PCT polyadenylated transcripts, in a sense orientation, is also observed at late passages in replicatively senescent primary fibroblasts and in cancer cells. Increased expression of specific transcripts from the 1q12 $\mathrm{PCT}$ region is correlated with a demethylation and with a decondensation of the locus (Enukashvily et al., 2007). Given the possible implication of PCT transcripts in heterochromatin structure, it is possible that the accumulation of PCT transcripts in senescent cells serves to maintain heterochromatin structure despite a loss of epigenetic repressive marks.

\section{How are CT and PCT regions transcribed?}

The complex expression pattern of mouse and human CT and PCT repeats (summarized in Fig. 5), suggests the existence of equally complex transcriptional or indeed post-transcriptional (processing from longer transcripts) for regulation of these patterns. In most of the cases reported in the literature, accumulation of CT and PCT transcripts occurs at a transcriptional level and is mediated by RNA polymerase II. This is the case in heat-shocked cells (Jolly et al., 2004; Rizzi et al., 2004), in senescent cells (Enukashvily et al., 2007) and during the course of the cell cycle (Lu and Gilbert, 2007). The fact that sense and antisense transcripts are not necessarily present in equal quantity within the cell suggests that, similar to what occurs in S.Pombe (Volpe et al., 2002; Nicolas et al., 2007), transcription is further governed by specific transcriptional regulatory complexes. It is however, not yet known if chromatin remodeling is the primary signal responsible for increased transcription of CT and PCT sequences. In any reported so far.
Mouse

Human

5. Physiological contexts leading to an accumulation of CT and PCT transcripts in heterogeneous size is observed upon stress, differentiation, DNA synthesis and development. in green) have been detected during differentiation and in confluent cells. While the accumulation of 120 nt long CT transcripts is thought to involve post-transcriptional mechanisms, PCT human, an accumulation of PCT transcripts, of heterogeneous size, is observed upon stress, development and in replicative senescent cells. No accumulation of CT transcripts has been

case, alteration of any of these different control steps is likely to participate to the accumulation of immature RNA molecules (Fig. 6). The following describes what is currently known on the precise mechanisms controlling accumulation of CT and PCT transcripts in mammalian cells.

\section{Implication of specific transcription factors}

Only a few actors involved in the transcriptional activation of repetitive $\mathrm{PCT}$ sequences have been identified so far. The only transcription factors which have been formally identified in the control of human PCT expression are Heat-Shock Factor 1 (HSF1) (Jolly et al., 2004) and tonicity Enhancer-Binding Protein (tonEBP) (Valgardsdottir et al., 2008). Upon stress, HSF1 directly binds to sat III sequences at the 9q12 locus and its absence prevents the accumulation of sat III transcripts in heat-shocked cells (Jolly et al., 2004). HSF2, which colocalizes with HSF1, could also play a role in the transcriptional activation of PCT sequences (Alastalo et al., 2003). TonEBP also accumulates at the $9 q 12$ locus in response to a hyperosmotic shock and its presence is essential to the transcriptional activation of sat III transcripts in cells submitted to a hyper-osmotic stress 


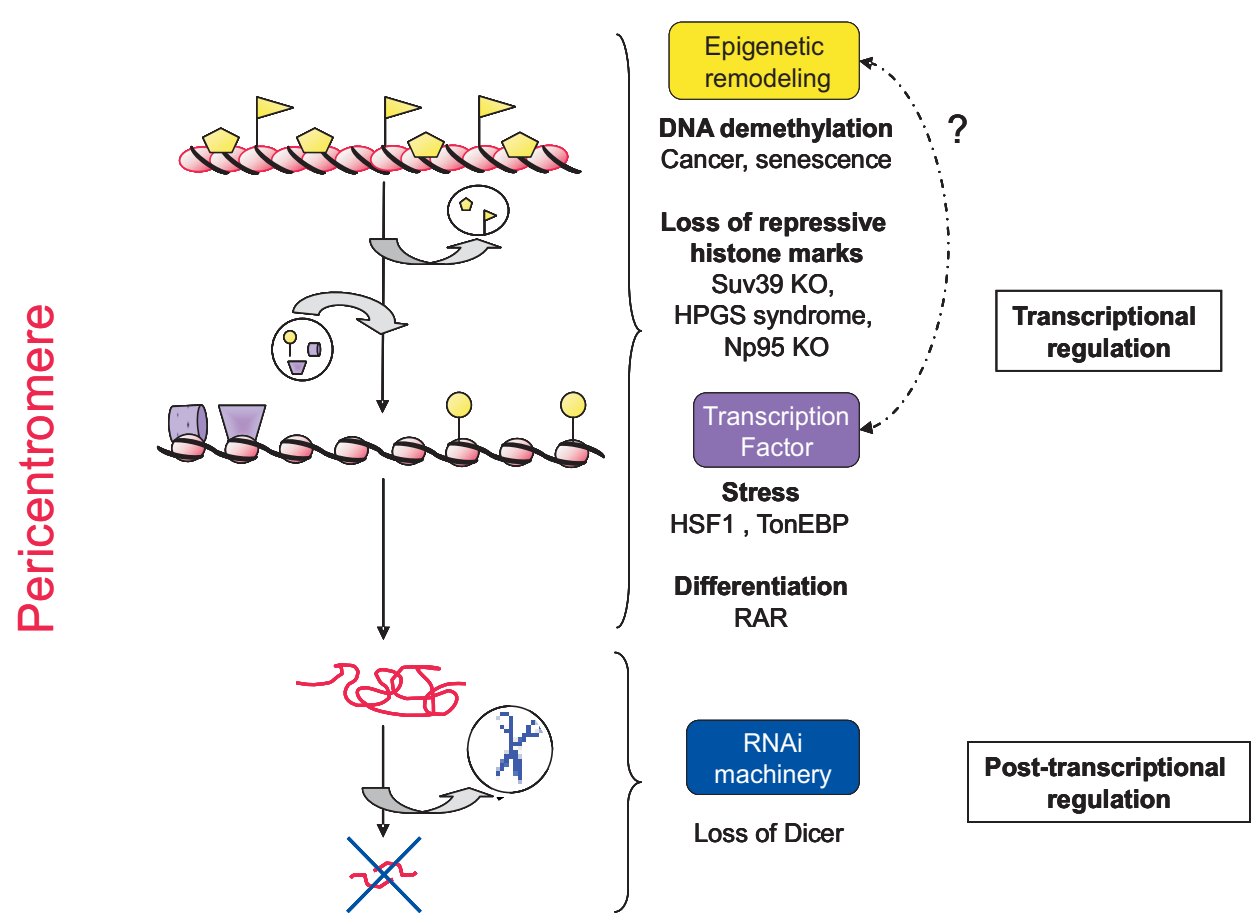

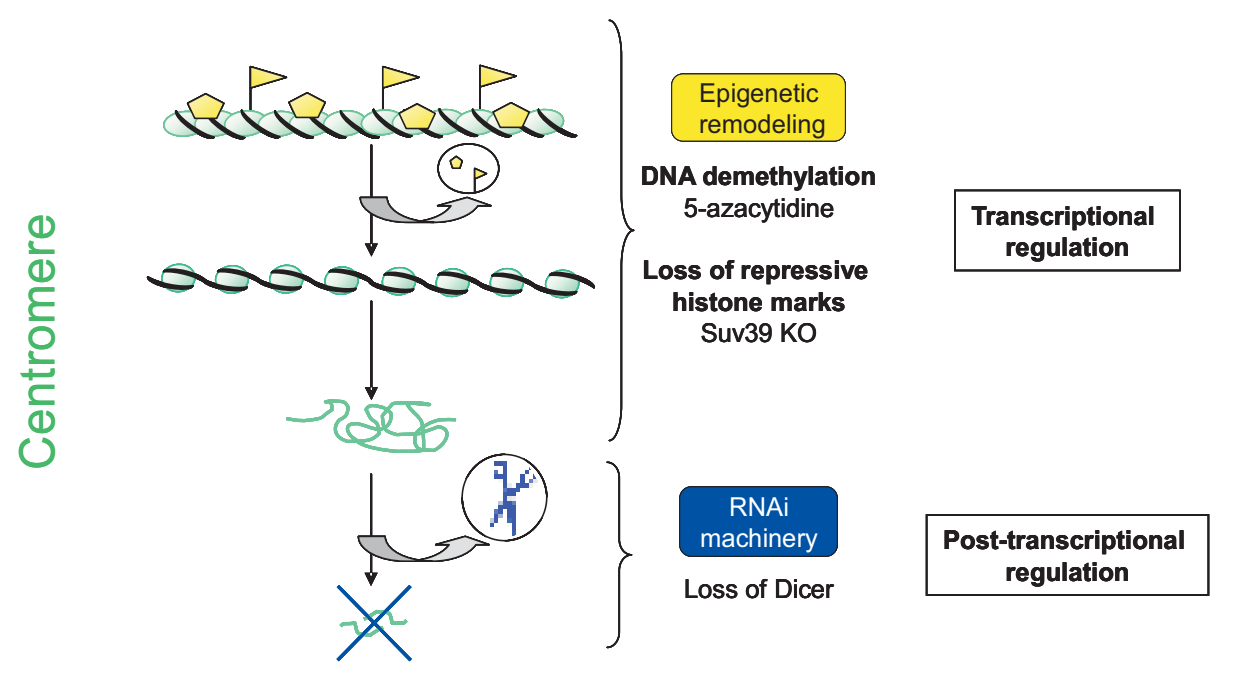

Fig. 6. Molecular mechanisms involved in the accumulation of CT and PCT specific transcripts. Accumulation of CT (represented in green) and PCT transcripts (represented in pink) is controlled by transcriptional mechanisms involving specific transcription factors (TFS, in purple) and epigenetic modifications (DNA demethylation and loss of repressive histone marks, in yellow). It is not clear at present if the activation of specific TFs in stressed cells is the initial event leading to chromatin remodeling and transcription of PCT sequences or if chromatin remodeling constitutes a prerequisite to the binding of TFs. It is also not clear if CT and PCT transcripts display similar functions as long and short RNA molecules and if the formation of small dsRNA constitute the ultimate step of the maturation of CT and PCT transcripts. The inhibition of post-transcriptional mechanisms such as RNAi machinery (in blue) is thought to contribute to the accumulation of long RNA molecules. A complete characterization of the different actors involved in the transcriptional activation and in the posttranscriptional maturation of CT and PCT is still missing.

(Valgardsdottir et al., 2008). In both cases, DNA sequences corresponding to putative binding sites for HSF1 (personal observation) and TonEBP (Valgardsdottir et al., 2008) have been identified in the genomic sequences corresponding to PCT regions. Moreover, the higher number of HSF putative binding sites identified in putative promoter regions governing the sense expression of PCT sequences probably hold the key to the accumulation of sat III transcripts mainly in the sense orientation.

Likewise, expression (Martens et al., 2005) or repression (Rudert et al., 1995) of equivalent murine PCT transcripts in response to RA may reflect the presence of retinoic acid receptor (RAR) binding sites within genomic PCT sequences. This hypothesis is reinforced by the isolation of PCT sequences with the ability to bind to RAR (Rudert and Gronemeyer, 1993). The specific influence of RA binding to such sites in PCT sequences is likely to depend on cellular context and action of specific cofactors (see above).

\section{Chromatin remodeling and transcrip- tion of CT and PCT sequences}

The different situations in which a variation of $C T$ and $P C T$ sequences expression has been observed, frequently correspond to distinct chromatin contexts. This is indeed the case for development and cell differentiation (Rasmussen, 2003; Probst and Almouzni, 2008), cancer (Brock et al., 2007), aging (Fraga and Esteller, 2007), replication (Gerbi and Bielinsky, 2002) and the response to stress (Jolly et al., 2004) all known to involve changes in DNA methylation and histone modifications. Since constitutive heterochromatin is characterized by a high level of DNA methylation, histone methylation particularly at $\mathrm{H} 3 \mathrm{~K} 9, \mathrm{H} 3 \mathrm{~K} 27$, and $\mathrm{H} 4 \mathrm{~K} 20$ - and by a low level of histone acetylation at $\mathrm{H} 3 \mathrm{~K} 9$, the nature of these epigenetic marks has been examined in relation to the transcriptional status of CT and PCT repetitive sequences. However, due to the difficulties related to quantification of repetitive $\mathrm{CT}$ and $\mathrm{PCT}$ DNA sequences from chromatin immuno-precipitates, particularly in humans, little information is available concerning the epigenetic status of 
these regions with respect to their transcriptional status.

\section{DNA methylation}

The effect of DNA methylation on the expression of satellite sequences has been analyzed in murine ES cells deficient in dnmt1 or dnmt3b, two DNA methyl transferases involved, respectively, in maintenance and de novo methylation of DNA. No variation of CT and PCT sequence expression was observed in these cells when compared to wild type ES cells (Lehnertz et al., 2003; Martens et al., 2005). The effect of DNA methylation has also been addressed by others, in murine erythroleukemic cultured cells treated with 5-azacytidine, a potent inhibitor of DNA methylation. MEL treated cells, display an increased expression of CT sequences, characterized by an accumulation of 120nt long transcripts (Bouzinba-Segard et al., 2006). This observation is in agreement with reports suggesting that the expression of satellite sequences, observed in senescent and cancer cells, could be facilitated by a demethylation of PCT repeats. Indeed, a constitutive expression of PCT sequences at the $1 \mathrm{q} 12$ locus is also observed in A431 epithelial carcinoma cells and in senescent embryonic lung MRC5 cells where the genome is globally highly hypomethylated (Enukashvily et al., 2007). Cells from patients affected with the ICF syndrome (Immunodeficiency, Centromeric instability and Facial anomalies) constitute a powerful model to study the relationship between DNA methylation and expression of pericentric sequences. ICF syndrome is characterized by a severe hypomethylation of PCT sequences. Chromosomes from cultured lymphocytes from ICF patients display a local decondensation of PCT regions associated with chromosomal rearrangements involving these regions (Ehrlich, 2003). However, the absence of strong constitutive expression of sat III sequences suggests that demethylation per se is not sufficient to enhance the expression of sat III sequences (Alexiadis et al., 2007). Moreover, the transcription of PCT sequences in heatshocked cells occurs in the context of highly methylated PCT region as no variation of DNA methylation is observed within PCT regions between heat-shocked and non heat-shocked cells (personal observation).

The link between DNA methylation and expression of repetitive sequences is still unclear and additional comparative analysis on different cell types should help to clarify this relationship. Although demethylation may facilitate transcription of repetitive sequences, the level of DNA methylation is not sufficient to discriminate between cells expressing or not CT and PCT sequences. The recent finding that inhibition of the class III histone deacetylase, SIRT1, causes a reactivation of silenced cancer genes without loss of promoter DNA hypermethylation (Pruitt et al., 2006) suggests that similar mechanisms may also contribute to the transcriptional activation of CT and PCT sequences, independent of DNA methylation.

\section{Histone modifications}

As for DNA methylation, little is known concerning the epigenetic status of heterochromatic regions with regard to variation of CT and PCT sequence expression. In ES mouse cells, transcription of PCT sequences occurs despite a high level of H3K9me3, H4K20me3, H3K27me3 repressive histone marks (Martens et al., 2005). Similarly, in terminal muscle differentiation a transcriptional activation of CT and PCT sequences occurs despite a higher level of histone $\mathrm{H} 3 \mathrm{~K} 9 \mathrm{me} 3$ and H4K20me3 across these regions (Terranova et al., 2005). These observations suggest that CT and PCT transcripts might be involved in the establishment and maintenance of heterochromatic specific marks in differentiating muscle cells. Although a loss of $\mathrm{H} 3 \mathrm{~K} 9 \mathrm{me} 3$ is not associated to the transcriptional activation of CT and PCT sequences, loss of Suv39 histone methyltransferase involved in H3K9 methylation nonetheless facilitates the expression and/or stabilization of CT and PCT transcripts which accumulate as dsRNA (Lehnertz et al., 2003; Martens et al., 2005).

The idea that a loss of repressive epigenetic marks could facilitate transcription of heterochromatic repetitive sequences is also suggested by observations made in fibroblasts from patients affected by the Hutchinson Gilford Progeria Syndrome (HGPS). HGPS, caused by the presence of an altered form of Lamin A, is characterized by a dramatic and rapid appearance of aging beginning in childhood. In HGPS cells a complete loss of H3K9me3, H3K27me3 and H4K20met3 and HP1 heterochromatic marks is correlated to constitutive expression of chromosome 9 PCT sequences. The absence of CT expression in HGPS cells suggests that the transcription of CT and PCT repeats do not involve similar epigenetic mechanisms (Shumaker et al., 2006). Since epigenetic information needs to be maintained through mitotic cell divisions, alterations of the machinery involved in the transmission of heterochromatic marks through mitosis is also likely to have impact on the expression of heterochromatic sequences. This is indeed the case for Np95 a cell cycle regulated nuclear histone-binding protein. Np95, which targets HDAC1 to specific promoters, is involved in the deacetylation of $\mathrm{H} 4 \mathrm{~K} 5$ and $\mathrm{K} 12$ after their integration in heterochromatic regions following replication. Np95 expression starts at the G1/S boundary and persists to the end of mitosis. Depletion of Np95 (Papait et al., 2007) results in increased expression of PCT sequences, suggesting that alteration of an initial post-replicative step involved in heterochromatin formation leads to a derepression of PCT sequences. This derepression is restricted to $\mathrm{PCT}$ and does not affect $\mathrm{CT}$ sequences (Papait et al., 2007), again illustrating the specific behavior of PCT with regard to CT sequences. Taken together, Np95 and Suv39 appear as essential components or actors in heterochromatin chromatin formation and maintenance. As such, it is likely that the alteration of heterochromatin structure in response to the absence of one of these actors is perceived as a positive signal for CT and PCT transcriptional activation in order to facilitate the reformation of heterochromatin.

Finally, chromatin remodeling is also involved in the transcriptional, heat shock-induced accumulation of sat III transcripts. In heat-shocked cells, binding of HSF1 to the PCT $9 q 12$ locus initiates a series of events ultimately leading to the transcriptional activation of these sequences. The most striking manifestation of chromatin remodeling, associated to the transactivation of PCT sequences, is the presence of acetylated chromatin foci forming at the 9q12 locus in heat-shocked cells (Jolly et al., 2004; Rizzi et al., 2004). It is however, not yet clear if the formation of these acetylated foci results from local de novo acetylation at the $9 q 12$ locus or from a global deacetylation of the rest of the genome, excluding the 9q12 locus. The histone acetyl transferase, CBP, has been shown to accumulate, when overexpressed, at the $9 q 12$ locus of heat-shocked cells, thereby supporting the notion of core histone de-novo acetylation at the $9 q 12$ locus as a causal event 
(Jolly et al., 2004). However, no evidence for the implication of a specific HAT exists in vivo. Chromatin immunoprecipitation experiments would be necessary to determine whether HSF1 binding precedes the formation of acetylated foci at the $9 q 12$ locus.

Interestingly, it has been reported that chromatin at the $9 q 12$ locus is composed of both open and compact chromatin fibers suggesting that the status of the $9 q 12$ locus might be different from that of other PCT regions and CT regions (Gilbert et al., 2004). This specific chromatin organization may favor heatinduced expression of PCT sequences at the 9q12 locus (Jolly et al., 2004; Rizzi et al., 2004).

\section{Post-transcriptional control of CT and PCT sequence expres- sion}

In S.Pombe, small-sized PCT transcripts, generated by Dicer, through targeting by the RITS complex, play a role in both the structure and function of heterochromatic regions (Verdel et al., 2004; Buhler and Moazed, 2007) (Fig. 1). Thus, by analogy to what occurs in the yeast model, long transcripts detected in mouse and human cells may represent precursors of small dsRNA. It is, however, important to note that validation of this hypothesis in mammalian cells requires consideration of the fact that the yeast genome is largely unmethylated. In this respect, and by analogy to Xist RNA, it is also possible that CT and PCT long transcripts might play a role in the actual shut down and/or maintenance of particular heterochromatin states, during cell stress for instance.

A role for small 20-30nt long dsRNA in human and mouse heterochromatin is, however, strongly suggested by data obtained in two different cellular models deficient for Dicer. In a chicken-human hybrid cell line containing human chromosome 21 , loss of Dicer expression leads to the accumulation of CT and PCT specific transcripts, ranging in size from 20-30nt up to several kb (Fukagawa et al., 2004). This accumulation results in cell death and also to premature sister chromatid separation. Similarly, an accumulation of long-sized CT and PCT transcripts correlating to severe defects in differentiation is also detected in mouse ES cells deficient for Dicer. Only in Dicer-expressing cells are CT and PCT specific transcripts detected as small dsRNA molecules with predominant signals at 150nt and 25-30nt (Kanellopoulou et al., 2005). The presence of 25-30nt species suggests that these RNA are generated by Dicer-dependent mechanism and thus might represent the functional equivalent of siRNAs specific for similar PCT sequences identified in S.pombe. Thus failure to detect these 25-30nt transcripts in other cellular systems (Bouzinba-Segard et al., 2006) may simply reflect their very low levels as a consequence of continuous and robust Dicer processing together with the fact that in mammalian cells transcription may be mostly RNA Polymerase II- and not RNA dependent RNA polymerase (RdRP)-dependent as in yeast. Interestingly, and in support of this, inverse correlations between PCT and Dicer transcript levels have been documented (Terranova et al., 2005).

\section{Conclusion}

In summary, we have reviewed the wide diversity of biological contexts in which CT and PCT sequence expression is observed. These transcripts are mostly detected as long molecules (more than 100bp) for which accumulation depends on both transcriptional and/or post-transcriptional mechanisms. Many questions still remain concerning the nature of the mechanisms involved in the control of their expression. The implication of transcription factors together with the observation that the sense of transcription is highly controlled suggests that these transcripts fulfill specific cellular functions and that their accumulation is not merely a consequence of read-through transcription in response to chromatin remodeling events. An interesting concept emerging from these different studies is that the accumulation of CT and PCT transcripts could constitute a good sensor to reveal epigenetic modifications of the genome such as those occurring in aging or cancer. Indeed, instability of specific constitutive heterochromatin compartments, notably loss of H4K20me3 (Fraga et al., 2005) and rearrangements affecting the pericentric regions of certain chromosomes (1q) have been observed in human B-cell non-Hodgkins lymphoma (Fournier et al., 2007). It will be of interest to determine the transcription status of CT and PCT sequences in these cases.

We have paid particular attention to evidence suggesting that, similar to S.Pombe, mouse and human CT and PCT transcripts play a role in heterochromatin structure and function. It is however likely that CT and PCT transcription mediate other cellular functions, such as position effect and transient sequestration of transcription factors and/or splicing factors under conditions of cellular or chromatin stress.

From these studies it appears that heterochromatin has only revealed a very small part of its secret message. More thorough characterization of non-coding CT and PCT RNA structure and function will be an important challenge for the future. Solving this enigma may prove vital in resolving at least some of the mysteries surrounding the role of constitutive heterochromatin in development, cell differentiation and responses to chromatin stress.

\section{Acknowledgements}

We thank Dr Caroline Jolly and Sabrina Fritah for critical reading of the manuscript. Work in the team 10 and 7 laboratories is supported by grants from the Institut National du Cancer (EPISTRESS project - Team 10), by Cancéropôle Lyon Auvergne Rhône Alpes (EpiPro, EpiMed) and by ARC ('ARECA epigenetics network'). Additional funding for Team 7 is provided by the Direction Régionale de la Recherche Clinique-CHU de Grenoble, Ligue Contre le Cancer - Comité de la Haute Savoie. Angeline Eymery is the recipient of a fellowship from the Fondation pour la Recherche Medicale. Mary Callanan is the recipient of an INSERM - Grenoble University hospital Interface Contract.

\section{References}

ALASTALO, T.P., HELLESUO, M., SANDQVIST, A., HIETAKANGAS, V., KALLIO, M. and SISTONEN, L. (2003). Formation of nuclear stress granules involves HSF2 and coincides with the nucleolar localization of Hsp70. J Cell Sci 116: 3557-3570.

ALEXIADIS, V., BALLESTAS, M.E., SANCHEZ, C., WINOKUR, S., VEDANARAYANAN, V., WARREN, M. and EHRLICH, M. (2007). RNAPol-ChIP analysis of transcription from FSHD-linked tandem repeats and satellite DNA. Biochim Biophys Acta 1769: 29-40.

AMOR, D.J., KALITSIS, P., SUMER, H. and CHOO, K.H. (2004). Building the centromere: from foundation proteins to $3 \mathrm{D}$ organization. Trends Cell Biol 14: 359-368.

ARAVIN, A., GAIDATZIS, D., PFEFFER, S., LAGOS-QUINTANA, M., LANDGRAF, P., IOVINO, N., MORRIS, P., BROWNSTEIN, M.J., KURAMOCHI-MIYAGAWA, 
S., NAKANO, T. et al. (2006). A novel class of small RNAs bind to MILI protein in mouse testes. Nature 442: 203-207.

BIAMONTI, G. (2004). Nuclear stress bodies: a heterochromatin affair? Nat Rev Mol Cell Biol 5: 493-498.

BOUZINBA-SEGARD, H., GUAIS, A. and FRANCASTEL, C. (2006). Accumulation of small murine minor satellite transcripts leads to impaired centromeric architecture and function. Proc Natl Acad Sci USA 103: 8709-8714.

BROCK, M.V., HERMAN, J.G. and BAYLIN, S.B. (2007). Cancer as a manifestation of aberrant chromatin structure. Cancer $J$ 13: 3-8.

BUHLER, M. and MOAZED, D. (2007). Transcription and RNAi in heterochromatic gene silencing. Nat Struct Mol Biol 14: 1041-1048.

CHEN, E.S., ZHANG, K., NICOLAS, E., CAM, H.P., ZOFALL, M. and GREWAL, S.I. (2008). Cell cycle control of centromeric repeat transcription and heterochromatin assembly. Nature 451: 734-737.

CHIODI, I., BIGGIOGERA, M., DENEGRI, M., CORIONI, M., WEIGHARDT, F., COBIANCHI, F., RIVA, S. and BIAMONTI, G. (2000). Structure and dynamics of hnRNP-labelled nuclear bodies induced by stress treatments. J Cell Sci 113: 4043-4053.

COHEN, A.K., HUH, T.Y. and HELLEINER, C.W. (1973). Transcription of satellite DNA in mouse L-cells. Can J Biochem 51: 529-532.

DENEGRI, M., CHIODI, I., CORIONI, M., COBIANCHI, F., RIVA, S. and BIAMONTI, G. (2001). Stress-induced nuclear bodies are sites of accumulation of premRNA processing factors. Mol Biol Cell 12: 3502-3514.

DENEGRI, M., MORALLI, D., ROCCHI, M., BIGGIOGERA, M., RAIMONDI, E., COBIANCHI, F., DE CARLI, L., RIVA, S. and BIAMONTI, G. (2002). Human chromosomes 9,12 , and 15 contain the nucleation sites of stress-induced nuclear bodies. Mol Biol Cell 13: 2069-2079.

EHRLICH, M. (2003). The ICF syndrome, a DNA methyltransferase 3B deficiency and immunodeficiency disease. Clin Immunol 109: 17-28.

ENUKASHVILY, N.I., DONEV, R., WAISERTREIGER, I.S. and PODGORNAYA, O.I. (2007). Human chromosome 1 satellite 3DNA is decondensed, demethylated and transcribed in senescent cells and in A431 epithelial carcinoma cells. Cytogenet Genome Res 118: 42-54.

FISHER, A.G. and MERKENSCHLAGER, M. (2002). Gene silencing, cell fate and nuclear organisation. Curr Opin Genet Dev 12: 193-197.

FOURNIER, A., FLORIN, A., LEFEBVRE, C., SOLLY, F., LEROUX, D. and CALLANAN, M.B. (2007). Genetics and epigenetics of $1 q$ rearrangements in hematological malignancies. Cytogenet Genome Res 118: 320-327.

FRAGA, M.F., BALLESTAR, E., VILLAR-GAREA, A., BOIX-CHORNET, M., ESPADA, J., SCHOTTA, G., BONALDI, T., HAYDON, C., ROPERO, S., PETRIE, K. et al. (2005). Loss of acetylation at Lys16 and trimethylation at Lys20 of histone $\mathrm{H} 4$ is a common hallmark of human cancer. Nat Genet 37: 391400.

FRAGA, M.F. and ESTELLER, M. (2007). Epigenetics and aging: the targets and the marks. Trends Genet 23: 413-418.

FUKAGAWA, T., NOGAMI, M., YOSHIKAWA, M., IKENO, M., OKAZAKI, T., TAKAMI, Y., NAKAYAMA, T. and OSHIMURA, M. (2004). Dicer is essential for formation of the heterochromatin structure in vertebrate cells. Nat Cell Biol 6: 784-791.

GAUBATZ, J.W. and CUTLER, R.G. (1990). Mouse satellite DNA is transcribed in senescent cardiac muscle. J Biol Chem 265: 17753-17758.

GERBI, S.A. and BIELINSKY, A.K. (2002). DNA replication and chromatin. Curr Opin Genet Dev 12: 243-248.

GILBERT, N., BOYLE, S., FIEGLER, H., WOODFINE, K., CARTER, N.P. and BICKMORE, W.A. (2004). Chromatin architecture of the human genome: generich domains are enriched in open chromatin fibers. Cell 118: 555-566.

GIRARD, A., SACHIDANANDAM, R., HANNON, G.J. and CARMELL, M.A. (2006). A germline-specific class of small RNAs binds mammalian Piwi proteins. Nature 442: 199-202.

GREWAL, S.I. and ELGIN, S.C. (2007). Transcription and RNA interference in the formation of heterochromatin. Nature 447: 399-406.

HAREL, J., HANANIA, N., TAPIERO, H. and HAREL, L. (1968). RNA replication by nuclear satellite DNA in different mouse cells. Biochem Biophys Res Commun 33: 696-701.

HEARD, E. (2004). Recent advances in X-chromosome inactivation. Curr Opin Cell
Biol 16: 247-255.

JEHAN, Z., VALLINAYAGAM, S., TIWARI, S., PRADHAN, S., SINGH, L., SURESH, A., REDDY, H.M., AHUJA, Y.R. and JESUDASAN, R.A. (2007). Novel noncoding RNA from human $Y$ distal heterochromatic block (Yq12) generates testisspecific chimeric CDC2L2. Genome Res 17: 433-440.

JOLLY, C. and LAKHOTIA, S.C. (2006). Human sat III and Drosophila hsr omega transcripts: a common paradigm for regulation of nuclear RNA processing in stressed cells. Nucleic Acids Res 34: 5508-5514.

JOLLY, C., METZ, A., GOVIN, J., VIGNERON, M., TURNER, B.M., KHOCHBIN, S. and VOURC'H, C. (2004). Stress-induced transcription of satellite III repeats. $J$ Cell Biol 164: 25-33.

JOLLY, C., MORIMOTO, R., ROBERT-NICOUD, M. and VOURC'H, C. (1997). HSF1 transcription factor concentrates in nuclear foci during heat shock: relationship with transcription sites. J Cell Sci 110 (Pt 23): 2935-2941.

KANELLOPOULOU, C., MULJO, S.A., KUNG, A.L., GANESAN, S., DRAPKIN, R., JENUWEIN, T., LIVINGSTON, D.M. and RAJEWSKY, K. (2005). Dicer-deficient mouse embryonic stem cells are defective in differentiation and centromeric silencing. Genes Dev 19: 489-501.

LEHNERTZ, B., UEDA, Y., DERIJCK, A.A., BRAUNSCHWEIG, U., PEREZBURGOS, L., KUBICEK, S., CHEN, T., LI, E., JENUWEIN, T. and PETERS, A.H. (2003). Suv39h-mediated histone H3 lysine 9 methylation directs DNA methylation to major satellite repeats at pericentric heterochromatin. Curr Biol 13: $1192-1200$.

LIN, H. (2007). piRNAs in the germ line. Science 316: 397.

LU, J. and GILBERT, D.M. (2007). Proliferation-dependent and cell cycle regulated transcription of mouse pericentric heterochromatin. J Cell Biol 179: 411-421.

MAISON, C., BAILLY, D., PETERS, A.H., QUIVY, J.P., ROCHE, D., TADDEI, A., LACHNER, M., JENUWEIN, T. and ALMOUZNI, G. (2002). Higher-order structure in pericentric heterochromatin involves a distinct pattern of histone modification and an RNA component. Nat Genet 30: 329-334.

MARTENS, J.H., O'SULLIVAN, R.J., BRAUNSCHWEIG, U., OPRAVIL, S., RADOLF, M., STEINLEIN, P. and JENUWEIN, T. (2005). The profile of repeat-associated histone lysine methylation states in the mouse epigenome. EMBO J 24: 800812.

METZ, A., SORET, J., VOURC'H, C., TAZI, J. and JOLLY, C. (2004). A key role for stress-induced satellite III transcripts in the relocalization of splicing factors into nuclear stress granules. J Cell Sci 117: 4551-4558.

MUCHARDT, C., GUILLEME, M., SEELER, J.S., TROUCHE, D., DEJEAN, A. and YANIV, M. (2002). Coordinated methyl and RNA binding is required for heterochromatin localization of mammalian HP1alpha. EMBO Rep 3: 975-981.

NICOLAS, E., YAMADA, T., CAM, H.P., FITZGERALD, P.C., KOBAYASHI, R. and GREWAL, S.I. (2007). Distinct roles of HDAC complexes in promoter silencing, antisense suppression and DNA damage protection. Nat Struct Mol Biol 14: 372-380.

PAPAIT, R., PISTORE, C., NEGRI, D., PECORARO, D., CANTARINI, L. and BONAPACE, I.M. (2007). Np95 is implicated in pericentromeric heterochromatin replication and in major satellite silencing. Mol Biol Cell 18: 1098-1106.

PRASANTH, K.V., SACCO-BUBULYA, P.A., PRASANTH, S.G. and SPECTOR, D.L. (2003). Sequential entry of components of the gene expression machinery into daughter nuclei. Mol Biol Cell 14: 1043-1057.

PROBST, A.V. and ALMOUZNI, G. (2008). Pericentric heterochromatin: dynamic organization during early development in mammals. Differentiation 76: 15-23.

PROSSER, J., FROMMER, M., PAUL, C. and VINCENT, P.C. (1986). Sequence relationships of three human satellite DNAs. $J$ Mol Biol 187: 145-155.

PRUITT, K., ZINN, R.L., OHM, J.E., MCGARVEY, K.M., KANG, S.H., WATKINS, D.N., HERMAN, J.G. and BAYLIN, S.B. (2006). Inhibition of SIRT1 reactivates silenced cancer genes without loss of promoter DNA hypermethylation. PLOS Genet 2: e40.

QUIVY, J.P., ROCHE, D., KIRSCHNER, D., TAGAMI, H., NAKATANI, Y. and ALMOUZNI, G. (2004). A CAF-1 dependent pool of HP1 during heterochromatin duplication. EMBO J 23: 3516-3526.

RASMUSSEN, T.P. (2003). Embryonic stem cell differentiation: a chromatin perspective. Reprod Biol Endocrinol 1: 100.

RIZZI, N., DENEGRI, M., CHIODI, I., CORIONI, M., VALGARDSDOTTIR, R., COBIANCHI, F., RIVA, S. and BIAMONTI, G. (2004). Transcriptional activation 
of a constitutive heterochromatic domain of the human genome in response to heat shock. Mol Biol Cell 15: 543-551.

RUDERT, F., BRONNER, S., GARNIER, J.M. and DOLLE, P. (1995). Transcripts from opposite strands of gamma satellite DNA are differentially expressed during mouse development. Mamm Genome 6: 76-83.

RUDERT, F. and GRONEMEYER, H. (1993). Retinoic acid-response elements with a highly repetitive structure isolated by immuno-selection from genomic DNA. $J$ Steroid Biochem Mol Biol 46: 121-133.

SHUMAKER, D.K., DECHAT, T., KOHLMAIER, A., ADAM, S.A., BOZOVSKY, M.R., ERDOS, M.R., ERIKSSON, M., GOLDMAN, A.E., KHUON, S., COLLINS, F.S. et al. (2006). Mutant nuclear lamin A leads to progressive alterations of epigenetic control in premature aging. Proc Natl Acad Sci USA 103: 8703-8708.

TERRANOVA, R., SAUER, S., MERKENSCHLAGER, M. and FISHER, A.G. (2005). The reorganisation of constitutive heterochromatin in differentiating muscle requires HDAC activity. Exp Cell Res 310: 344-356.

VALGARDSDOTTIR, R., CHIODI, I., GIORDANO, M., ROSSI, A., BAZZINI, S., GHIGNA, C., RIVA, S. and BIAMONTI, G. (2008). Transcription of Satellite III non-coding RNAs is a general stress response in human cells. Nucleic Acids
Res 36: 423-434.

VERDEL, A., JIA, S., GERBER, S., SUGIYAMA, T., GYGI, S., GREWAL, S.I. and MOAZED, D. (2004). RNAi-mediated targeting of heterochromatin by the RITS complex. Science 303: 672-676.

VISSEL, B. and CHOO, K.H. (1987). Human alpha satellite DNA consensus sequence and conserved regions. Nucleic Acids Res 15: 6751-6752.

VOLPE, T.A., KIDNER, C., HALL, I.M., TENG, G., GREWAL, S.I. and MARTIENSSEN, R.A. (2002). Regulation of heterochromatic silencing and histone H3 lysine-9 methylation by RNAi. Science 297: 1833-1837.

WONG, A.K. and RATTNER, J.B. (1988). Sequence organization and cytological localization of the minor satellite of mouse. Nucleic Acids Res 16: 11645-11661.

WOOD, V.GWILLIAM, R.RAJANDREAM, M.A.LYNE, M.LYNE, R.STEWART, A.SGOUROS, J.PEAT, N.HAYLES, J.BAKER, S. et al. (2002). The genome sequence of Schizosaccharomyces pombe. Nature 415: 871-880.

WU, R., SINGH, P.B. and GILBERT, D.M. (2006). Uncoupling global and fine-tuning replication timing determinants for mouse pericentric heterochromatin. $J$ Cell Biol 174: 185-194.

\section{Further Related Reading, published previously in the Int. J. Dev. Biol.}

See our Special Issue Fertilization edited by Paul M. Wassarman and Victor D. Vacquier at: http://www.ijdb.ehu.es/web/contents.php?vol=52\&issue=5-6

The molecular evolution of sperm zonadhesin

Holger Herlyn and Hans Zischler

Int. J. Dev. Biol. (2008) 52: 781-790

Gene mapping of sperm quality parameters in recombinant inbred strains of mice Aniela Golas, Anna Dzieza, Katarzyna Kuzniarz and Jozefa Styrna Int. J. Dev. Biol. (2008) 52: 287-293

Regulated RNA processing in the control of Arabidopsis flowering Victor Quesada, Caroline Dean and Gordon G. Simpson Int. J. Dev. Biol. (2005) 49: 773-780

A new gene in Drosophila melanogaster, Ravus, the phantom of the modifier of position-effect variegation Su(var)3-7.

Marion Delattre, Anne Spierer, Nicolas Hulo and Pierre Spierer

Int. J. Dev. Biol. (2002) 46: 167-171

X-chromosome activity: impact of imprinting and chromatin structure. R V Jamieson, P P Tam and M Gardiner-Garden Int. J. Dev. Biol. (1996) 40: 1065-1080

2006 ISI **Impact Factor $=3.577^{* *}$

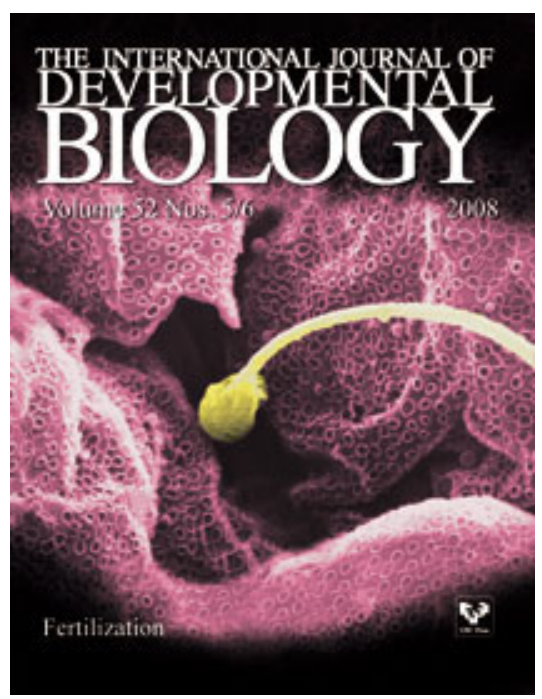

